\title{
Experimental Research on Floodplain Storage Inundation: Preliminary Results
}

\author{
Francesco De Paola (Corresponding author) \\ Dipartimento di Ingegneria Idraulica, Geotecnica e Ambientale \\ Università degli studi di Napoli "Federico II", via Claudio, 21-80125 Napoli, Italy \\ E-mail: depaola@unina.it \\ Gustavo Marini \\ Dipartimento di Ingegneria, Università degli Studi del Sannio \\ piazza Roma, 21-82100 Benevento, Italy \\ E-mail: gustavo.marini@unisannio.it
}

Received: November 14, $2011 \quad$ Accepted: November 23, $2011 \quad$ Published: December 31, 2011

doi:10.5539/eer.v1n1p53 URL: http://dx.doi.org/10.5539/eer.v1n1p53

\begin{abstract}
Among control structures in flood management, floodplain storage represents one of the most effective measures, since they hold part of flood volume into a delimited area, thus reducing the peak discharge.

One-dimensional models are quick and practical and are often based on the hypothesis of horizontal water surface in the floodplain during storage filling. This assumption need to be verified by means of experimental test, which are really difficult to assess also because tests requiring many costs to achieve prototypes and physical models.

To this aim the present paper shows preliminary results of an experimental investigation to assess the reliability of level pool routing in design of on-stream floodplain storages. Experimental tests performed with reference to on-stream floodplain prototype, showed that assumed hypothesis is correct during storage filling. Results obtained by means of numerical model based on level pool routing hypothesis are very near to experimental measures. Furthermore two synthetic indexes, which characterize hydraulic behavior of floodplain storage, were calculated for each test. It is shown that very simple linear relationship exists between these two indexes exists so this linear equation can be easily used to define the storage volume in preliminary design.
\end{abstract}

Keywords: Flood control, Floodplain, Hydraulic risk mitigation, Experimental tests

\section{Introduction}

Risks due to floods are higher in lowland areas especially when those are highly urbanized. In some cases, these events can cause deaths, damages and important economic losses.

For the purpose of reducing flood risk, different solutions were studied. Among the structural measures we find the floodplain storage. It temporary stores part of the flood volume which is released back to the river by means of outflow discharge values less than the maximum which can safely flow downstream.

Two-dimensional flood models are prime candidates for parallel computing, but traditional methods/equipment are more complex in terms of code refactoring and hardware setup. In addition, these hardware systems may not be available or accessible to modelers conducting flood analyses. In recent years several studies have been carried out for flood models developing. Papanicolaou et al (Papanicolaou, A. N., Elhakeem, M., \& Wardman, B., 2011) has evaluated the predictive capability of a two-dimensional (2D)-hydrodynamic model, the finite-element surface water modeling system (FESWMS), to describe adequately the flow characteristics around emergent bendway weir structures. Rahman et al (Rahman, M., Arya, D. S., Goel, N. K., \& Dhamy, A. P., 2011) conducted a study in the Teesta subcatchment in Bangladesh for determining design flood flows and corresponding flood stages for different return periods using frequency analysis and MIKE 11 model.

Scharffenberg \& Kavvas (Scharffenberg, W. A. \& Kavvas, M. L., 2011) studied the flood wave routing problem 
from a probabilistic point of view using the kinematic wave model. A physics-based, distributed hydrologic model (Vflo) was used to evaluate the effects of urbanization and detention storage on watershed stream flows with grid cells as $\mathrm{km}^{2}$ (Fang, Z., Zimmer, A., Bedient, P. B., et al., 2010). An application of the Hydrologic Simulation Program-FORTRAN (HSPF) model was developed for the entire Illinois River basin (Lian, Y., Chan, I. C., Xie, H., et al., 2010). They have coupled a calibrated hydraulic model, one-dimensional unsteady flow through a full network of open channels (UNET), to improve flow routing accuracy and the overall performance of the HSPF model. Kuiry et al. (Kuiry, S. N., Sen, D., \& Bates, P. D., 2010) introduced a simplified numerical model for simulation of floodplain inundation based on storage cell model and diffusive-wave approximated equation. Results are compared with those predicted by a two-dimensional (2D) finite volume model on hypothetical river-floodplain domains.

Two-dimensional models can generate difficulties (Freeman, G. E., Sundararaghavan, H., \& Heyen, J., 2003), in particular for preliminary sizing of floodplain storages in relatively flat areas, since they are data intensive and require advanced modeling capabilities. Consequently, it is often suggested to adopt, in particular during emergency flood management or preliminary structures sizing, simpler one-dimensional models, based on level pool reservoir (or uniform storage) hypothesis.

Horn (Horn, D. R., 1987) provided some charts for a direct estimation of the peak outflow discharge varying input hydrograph shape, storage and outlets. The proposed approach assumed a dimensionless inflow hydrograph and the stored volume depended exponentially on the outflow discharge. McEnroe (McEnroe, B. M., 1992) showed that a bottom outlet is more efficient than a spillway in flood storage management and proposed two equations for a quick design of flood storage. Basha (Basha, H. A., 1994) derived an analytical solution for the non linear reservoir routing, by introducing simplifications on storage geometry and inflow hydrograph, resulting in peak reduction ratio quadratic function of the storage ratio. Afterwards he obtained an approximate solution (Basha, H. A., 1995) by a two-term perturbation expansion whereby the zero-order is the linear solution and the first-order term is the correction. Akan (Akan, A. O., 1989; Akan, A. O., 1990) proposed a method for sizing detention ponds and outlet facilities for multiple return periods. The method is based on the usual reservoir-routing technique that couples the hydrologic-storage equation with an expression describing the flow through the outlet structure. The equations are rearranged in terms of several dimensionless parameters. The generalized results are presented in chart form.

Assuming that one-dimensional model are useful and considering that level pool routing procedures are generally accepted in reservoir and storage design thus experimental tests are fundamental to verify such hypothesis reliability. Experimental investigations were conducted at Department of Hydraulic, Geotechnical and Environmental Engineering of "Federico II" Naples University by reproducing filling and emptying of on-stream floodplain storages.

Experiments were performed on floodplain with different geometry, peak inflow discharge and shape of the input hydrograph.

\section{Experimental Setup}

Experimental setup allows to make tests varying different characteristics as well as magnitude and shape of inflow hydrograph, dimensions of outflow, flooded area dimension, etc. A planimetric sketch of the installation is shown in Figure 1. In this figure two configurations can be distinguished, they are different in particular for flooded area as well as discussed in what follows. The experimental prototype is made of: a stilling basin to dissipate exceeding energy and provide for accurate inflow discharge measurement using a rectangular weir; a $0.4 \%$ slope rectangular channel $h_{c}=0.30 \mathrm{~m}$ high and $0.45 \mathrm{~m}$ wide. At the end of the channel, a flood gate was arranged in order to produce flooding into the embanked storage area when orifice flow establishes; and an outflow tank for providing the flow intake into laboratory storage under the floor. From this storage two pumps convey the water to the storage tank where free surface is approximately five meters from the floor. From this reservoir the water goes to the model by means of hydraulic circuit.

Inlet structure is a vertical concrete wall supporting a plexiglass sharp crested weir. Inflow discharge $Q_{i}$ was calculated according to the rectangular weir equation:

$$
Q_{i}=C_{w} l_{w} h^{\prime} \sqrt{2 g h^{\prime}}
$$

in which $C_{w}=$ weir discharge coefficient, $l_{w}=$ notch width, $h^{\prime}=$ head on the weir and $g=$ gravitational acceleration. To accurately predict the flowrate over inlet weir, a volumetric method was used to calibrate discharge coefficient. Due to small deviations in discharge coefficients calculated at several discharges ranging between 10 and $60 \mathrm{l} / \mathrm{s}$, 
the discharge coefficient was assumed constant over the investigated range and equal to $C_{w}=0.465$

When the water level in the channel is less than the outlet height the flood gate does not work. When the water level increases flood gate induces backwater effects and storage area is flooded, thus reducing the downstream peak discharge. Outflow discharge $Q_{o}$ was calculated according to the orifice theory:

$$
Q_{o}=C_{o} A_{o} \sqrt{2 g(h-s / 2)}
$$

in which $C_{o}=$ orifice discharge coefficient, $A_{o}=$ area of the floodgate outlet $\left(A_{o}=l_{o} s\right.$, where $l_{o}$ and $s$ are respectively the width and the height of the outlet).

During weir coefficient calibration the inflow discharge is known; when steady state flow was achieved the outflow discharge equals the inflow rate, so the water level upstream of the gate was measured and the discharge coefficient was deduced. Figure 2 shows orifice discharge coefficient calculated by means of this approach. Since discharge coefficients exhibit small deviations varying the flow-rate, a constant value was assumed.

Heads on the weir and orifice were measured by means of two resistive level probes: first one in the stilling basin and second one upstream of the floodgate in the channel (Figure 1). The probes are by Edif, model Level3 with 400 $\mathrm{mm}$ measurement range and sensitivity ranging from $1 \mathrm{~V} / 100 \mathrm{~mm}$ to $2.5 \mathrm{~V} / 100 \mathrm{~mm}$. The probes were calibrated before each test to correlate the measured difference in electric potential $\Delta V$ to the water level, exhibiting a strongly linear relationship.

As abovementioned, two different configurations were analyzed in order to investigate the influence of flooded area dimensions. In greater detail, in configuration 1 the floodplain area was set to approximately $29 \mathrm{~m}^{2}$ and a concrete bottom surface was considered. In configuration 2 the floodplain area was increased to approximately 69 $\mathrm{m}^{2}$ (Figure 1).

For each configuration stage-area curve is been defined by means of experimental measure. First of all on the surface of floodplain a grid was drawn to compute the portion of the entire surface wetted by the water during filling. The flooded area was slowly filled. During flooding the water level and the wetted area were measured. Stage-area curves are shown for both configurations in Figure 5; analyzed floodplains are substantially flat, although not negligible bottom irregularities are present. Full details of analyzed configurations are given in Table 1.

\section{Comparison between Theoretical and Experimental Results}

Assuming horizontal free surface during the flooding of the area, the channel water levels $h$ can be estimated by numerical integration of the following differential equation:

$$
\frac{d h}{d t}=\frac{1}{S_{c}+S(z)}\left[Q_{i}(t)-C_{o} A_{o} \sqrt{2 g(h-s / 2)}\right]
$$

in which $S_{c}$ is the channel area, $S(z)$ is the floodplain flooded area, which was assumed to vary as the floodplain water level $z=h-h_{c}$ increases (stage-area curves, Figure 2) to take into account the bottom irregularities. Eq. (3) holds even during draining phase, in which $Q_{i}=0$, thus:

$$
\frac{d h}{d t}=-\frac{1}{S_{c}+S(z)}\left[C_{o} A_{o} \sqrt{2 g(h-s / 2)}\right]
$$

In figures 3 and 4 hydrograph and channel water level of configuration 1 experiment are depicted. In greater detail, in Figure 3 the experimental channel water levels measured upstream of the floodgate $\left(h_{\text {exp }}\right)$ were compared with those calculated by Eqs. (3) and (4) $\left(h_{n u m}\right)$. Figure 4 shows experimental inflow discharge $\left(Q_{i, \text { exp }}\right)$, experimental outflow discharge $\left(Q_{o, \text { exp }}\right)$ and outflow discharge $\left(Q_{o, \text { num }}\right)$ calculated by means of orifice flow equation (5):

$$
Q_{o, \text { num }}=C_{o} A_{o} \sqrt{2 g\left(h_{\text {num }}-s / 2\right)}
$$

Results of all tests as well as shown figures explain the fairly good agreement between measured and theoretical values both in terms of hydrographs and water level, so configuration 1 experiments assess the reliability of uniform storage hypothesis. In configuration 2 area of floodplain was increased to investigate the scale factor influence. Some tests analogous to those of configuration 1 were carried out varying discharge value and shape hydrograph. Water levels and hydrographs for a test of configuration 2 were depicted in Figures 5 and 6. During filling phase, the behavior is the same of smaller floodplain. Numerical and experimental values are similar in fact the differences in Figure 5 during filling phase are negligible. Water level were reducing during draining phase in 
which they assume different values between experimental and numerical. Figure 5 shows for water level as well as Figure 6 for discharge these differences. This phenomenon is due to bottom irregularities which create small capacities where the water is temporary stored and slowly come out after emptying end. This discrepancy, however, is concerning just the draining phase which does not affect sizing methods that usually depend only on filling phase.

Carrying out the test on the prototype that has bottom irregularities are useful because in the real case floodplain storage are not man-made facilities but consist of delimited natural area which in themselves present greater land irregularities, presence of obstacle for water flow as well as vegetation, trees etc. could modify filling phase, and consequently sizing method reliability. For this reason some experimental tests have been planned to better explore this point; the results will be discussed in next paper.

\section{A Comprehensive Interpretation of Results}

A relationship between peak reduction ratio $\eta=Q_{o, \max } / Q_{i, \max }$ and storage ratio $w=W_{s} / W_{f}$ was found. $W_{f}$ was calculated as the area under inflow hydrograph limited by intersections with outflow hydrograph, $W_{s}$ as the area bounded by inflow and outflow hydrographs (Figure 7). After each test, a point in the $w, \eta$ plan could be determined, as depicted in Figure 8; the peak reduction ratio ranged between 0.5 and 0.8 , covering the values commonly adopted in floodplain storage sizing. Experimental data were compared with theoretical values inferred from Marone (Marone, V., 1971), Horn (Horn, D. R., 1987), Basha (Basha, H. A., 1994) and McEnroe (McEnroe, B. M., 1992). For the sake of brevity the explanation of considered models is omitted, for greater details please refer to original papers.

Some validation indexes (Judi, D. R., Burian, S. J., \& McPherson, T. N., 2011) related to correlation between theoretical and experimental values were calculated. Validation indexes are the coefficient of determination $\left(r^{2}\right)$, the Nash-Sutcliffe efficiency $(E)$ and the index of agreement $(i a)$. The coefficient of determination measures the amount of variance of observations that can be explained by the theoretically derived values. Likewise, the Nash-Sutcliffe efficiency that varying between 1 (perfect fit) and - $\infty$ is defined as one minus the sum of the absolute squared differences between the predicted and observed values normalized by the variance of the observed values.

The index of agreement represents the ratio of the mean square error and the potential error; the potential error represents the largest value that squared difference of each pair can attain. The range of $i a$ is similar of $r^{2}$ and lies between 0 (no correlation) and 1 (perfect fit).

The values of calculated indexes are given in Table 2 for both configuration and for all theoretical models. In greater detail, for both investigated configurations, theoretical model which best fits experimental data is that one simplest to use rather Marone model; the line of equation $\eta=1-w$, which was proposed by Marone (Marone, V., 1971) to represent a suitable relationship between the peak reduction ratio and the storage ratio, have highest value of all validation indexes. That relationship does not depend on storage and outlet size, peak discharge and hydrograph shape and can be reliably adopted for preliminary sizing of on-stream floodplain storage.

Validation index values of all other methods are quite good, confirming that flood volume represent the most important issue when dealing with storage routing, whereas shape hydrograph and peak discharge play only a minor role.

\section{Conclusion}

Some experimental tests to verify the reliability of the level pool routing in floodplain storage hydraulic design were performed. Tests are carried out varying inflow hydrographs (shape and peak discharge), test duration and considering two configuration of storage area. Preliminary results which are discussed in the present paper show good agreement between experimental measurements and numerical values. That confirms the reliability of level pool routing hypothesis in the preliminary sizing of on-stream floodplain storage at least for considered configuration. A simple numerical model can be used in floodplain analysis just knowing flooded area characteristics and inflow hydrograph.

Furthermore two synthetic indexes, often used for characterize hydraulic behavior of floodplain storage, were calculated for each test. The analysis of the correlation between two indices was investigated and appeared to be almost linear. That suggested that Marone model gives best evaluation of this correlation, among the numerical models proposed in literature. However more tests have to be carried out to give greater value to these conclusions.

\section{References}

Akan, A. O. (1989). Detention pond sizing for multiple return periods. J. of Hydraulic Engineering, 115(5), 650-664. http://dx.doi.org/10.1061/(ASCE)0733-9429(1989)115:5(650) 
Akan, A. O. (1990). Single outlet detention-pond analysis and design. J. Irrig. and Drain Eng., 115(5), 527-536. http://dx.doi.org/10.1061/(ASCE)0733-9437(1990)116:4(527)

Basha, H. A. (1994). Non linear reservoir routing: a particular analytical solution. J. of Hydraulic Engineering, 120(5), 624-632. http://dx.doi.org/10.1061/(ASCE)0733-9429(1994)120:5(624)

Basha, H. A. (1995). Routing Equations for Detention Reservoirs. J. of Hydraulic Engineering, 121(12), 885-888. http://dx.doi.org/10.1061/(ASCE)0733-9429(1995)121:12(885)

Fang, Z., Zimmer, A., Bedient, P. B., Robinson, H., Christian, J., \& Vieux, B. E. (2010). Using a Distributed Hydrologic Model to Evaluate the Location of Urban Development and Flood Control Storage. J. Water Resour. Plng. and Mgmt, 136, 597. http://dx.doi.org/10.1061/(ASCE)WR.1943-5452.0000066

Freeman, G. E., Sundararaghavan, H., \& Heyen, J. (2003). Two-Dimensional Modeling of Floodplains. Necessary or Excessive? Two Case Studies. Proc. World Water Congress, 118-140.

Horn, D. R. (1987). Graphic estimation of peak flow reduction in reservoirs. J. of Hydraulic Engineering, 113(11), 1441-1450. http://dx.doi.org/10.1061/(ASCE)0733-9429(1987)113:11(1441)

Judi, D. R., Burian, S. J., \& McPherson, T. N. (2011). Two-Dimensional Fast-Response Flood Modeling: Desktop Parallel Computing and Domain Tracking. J. Computing in Civ. Eng., 25, 184. http://dx.doi.org/10.1061/(ASCE)CP.1943-5487.0000064

Kuiry, S. N., Sen, D., \& Bates, P. D. (2010). Coupled 1D-Quasi-2D Flood Inundation Model with Unstructured Grids. J. Hydrologic Engineering, 136, 493. http://dx.doi.org/10.1061/(ASCE)HY.1943-7900.0000211

Lian, Y., Chan, I. C., Xie, H., \& Demissie, M. (2010). Improving HSPF Modeling Accuracy from FTABLES: Case Study for the Illinois River Basin. J. Hydrologic Engineering, 15, 642. http://dx.doi.org/10.1061/(ASCE)HE. 1943-5584.0000222

Marone, V. (1971). Calcolo di massima di un serbatoio di laminazione. L'Energia Elettrica, 9, 561-567.

McEnroe, B. M. (1992). Preliminary sizing of detention reservoirs to reduce peak discharges. J. of Hydraulic Engineering, 118(11), 1540-1549. http://dx.doi.org/10.1061/(ASCE)0733-9429(1992)118:11(1540)

Papanicolaou, A. N., Elhakeem, M., \& Wardman, B. (2011). Calibration and Verification of a 2D Hydrodynamic Model for Simulating Flow around Emergent Bendway Weir Structures". J. Hydrologic Engineering, 137, 75. http://dx.doi.org/10.1061/(ASCE)HY.1943-7900.0000280

Rahman, M., Arya, D. S., Goel, N. K., \& Dhamy, A. P. (2011). Design Flow and Stage Computations in the Teesta River, Bangladesh, Using Frequency Analysis and MIKE 11 Modeling. J. Hydrologic Engineering, 16, 176. http://dx.doi.org/10.1061/(ASCE)HE.1943-5584.0000299

Scharffenberg, W. A. \& Kavvas, M. L. (2011). Uncertainty in Flood Wave Routing in a Lateral-Inflow-Dominated Stream. J. Hydrologic Engineering, 16, 165. http://dx.doi.org/10.1061/(ASCE)HE.1943-5584.0000298

Table 1. Characteristics of analyzed configurations

\begin{tabular}{|l|l|l|l|l|l|}
\hline configuration & $\mathrm{S}\left[\mathrm{m}^{2}\right]$ & $L_{c}[\mathrm{~m}]$ & $C_{w}[-]$ & $C_{o}[-]$ & $\mathrm{N}^{0}$ Tests \\
\hline 1 & 29.12 & 11.21 & 0.465 & 0.640 & 64 \\
\hline 2 & 69.20 & 15.96 & 0.465 & 0.612 & 41 \\
\hline
\end{tabular}

Table 2. Validation indexes for each theoretical model and both configurations

\begin{tabular}{|l|l|l|l|l|l|l|l|l|}
\hline \multirow{2}{*}{ validation index } & \multicolumn{4}{l}{ configuration 1 } & \multicolumn{3}{l|}{ configuration 2 } \\
\cline { 2 - 10 } & Marone & Basha & McEnroe & Horn & Marone & Basha & McEnroe & Horn \\
\hline$r^{2}$ & 0.534 & 0.541 & 0.543 & 0.540 & 0.721 & 0.722 & 0.725 & 0.724 \\
\hline$E$ & 0.307 & -4.520 & -2.879 & -2.164 & 0.532 & -2.402 & -1.290 & -0.910 \\
\hline$i a$ & 0.834 & 0.491 & 0.567 & 0.603 & 0.884 & 0.601 & 0.688 & 0.719 \\
\hline
\end{tabular}




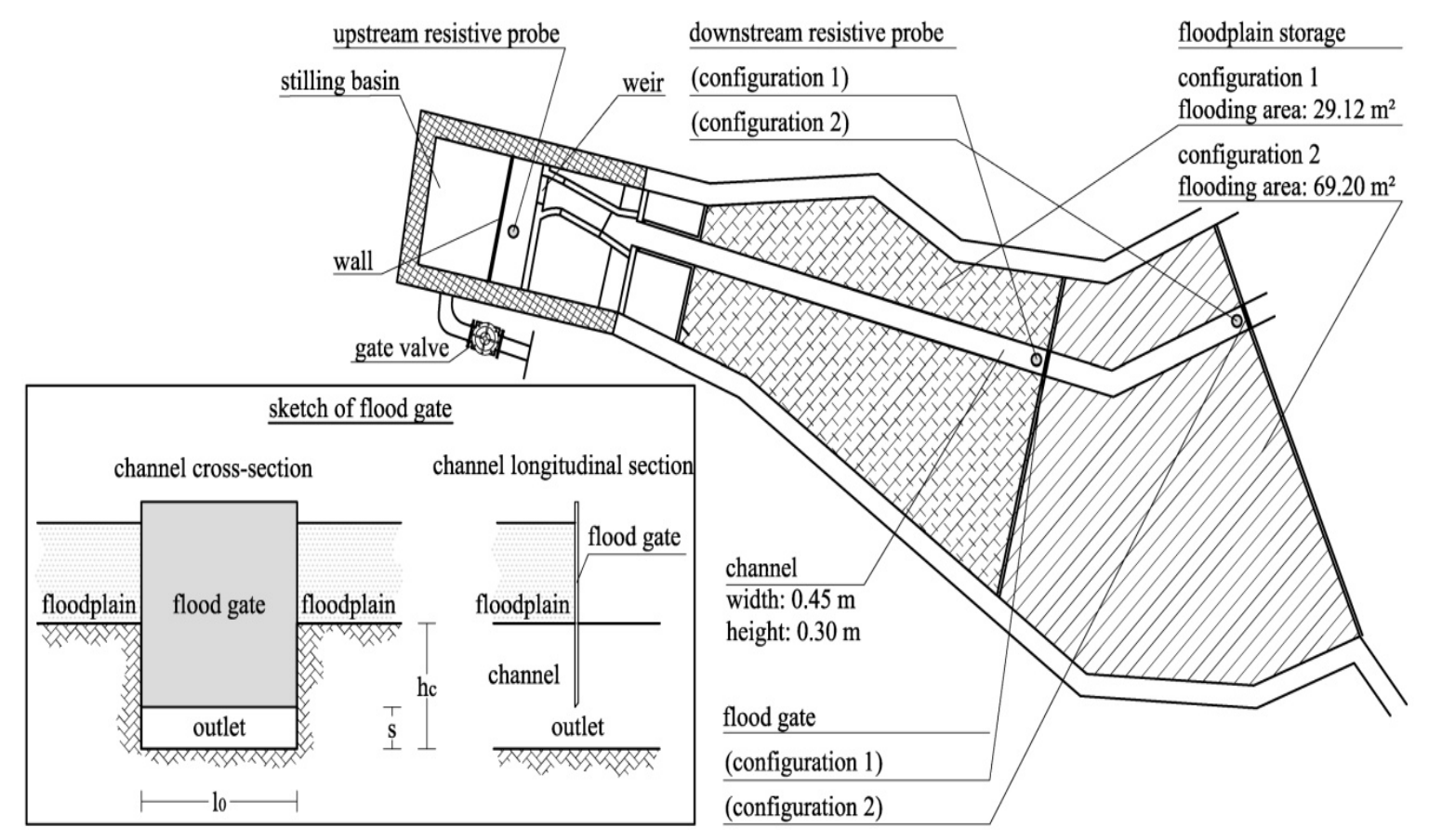

Figure 1. Experimental setup plan view

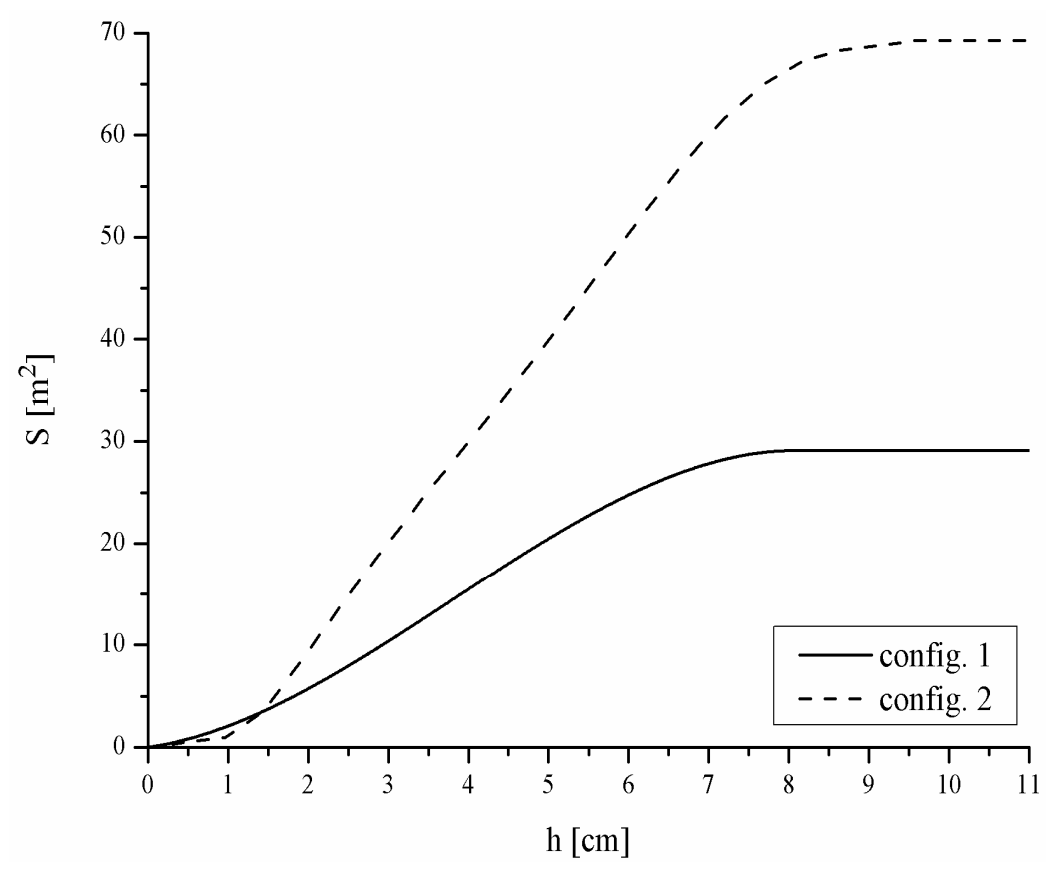

Figure 2. Stage-Area curves 


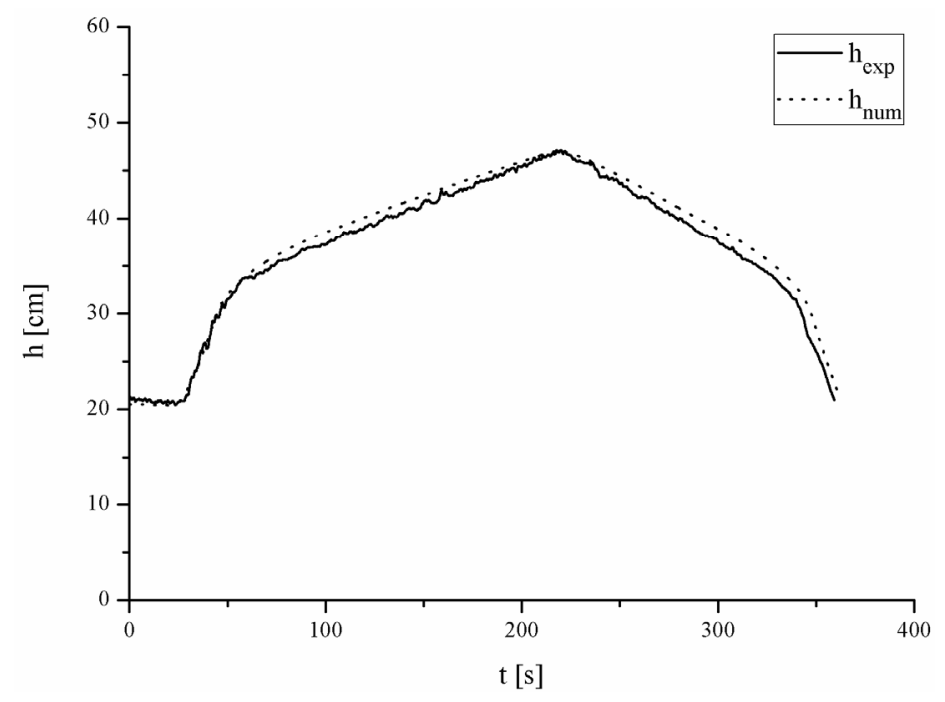

Figure 3. Water level upstream of the floodgate for configuration 1 experiment

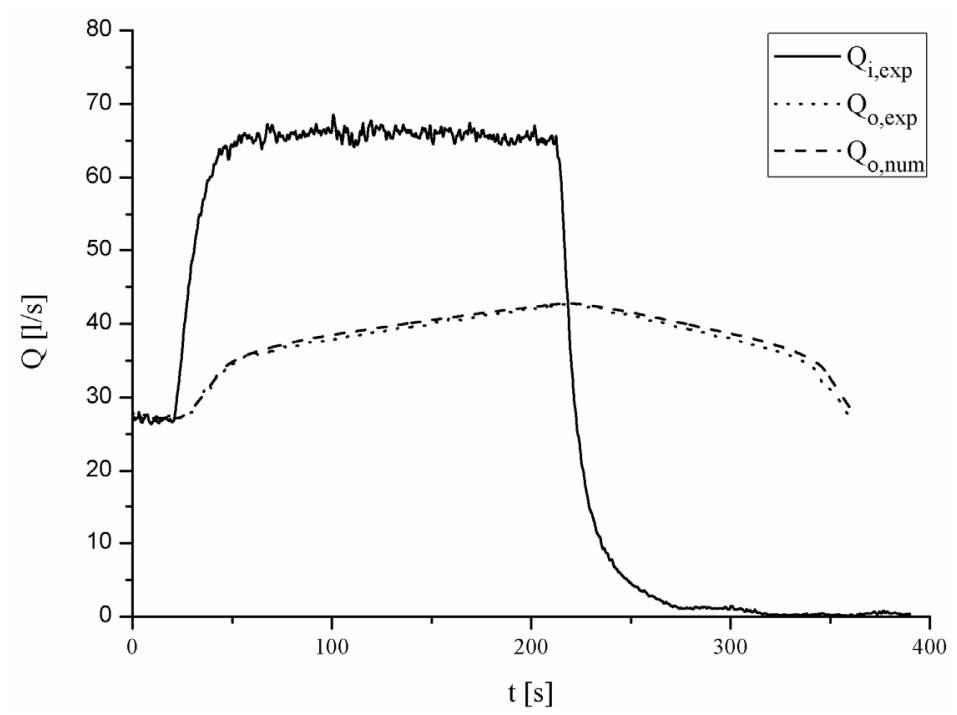

Figure 4. Inflow and outflow hydrographs for configuration 1 experiment

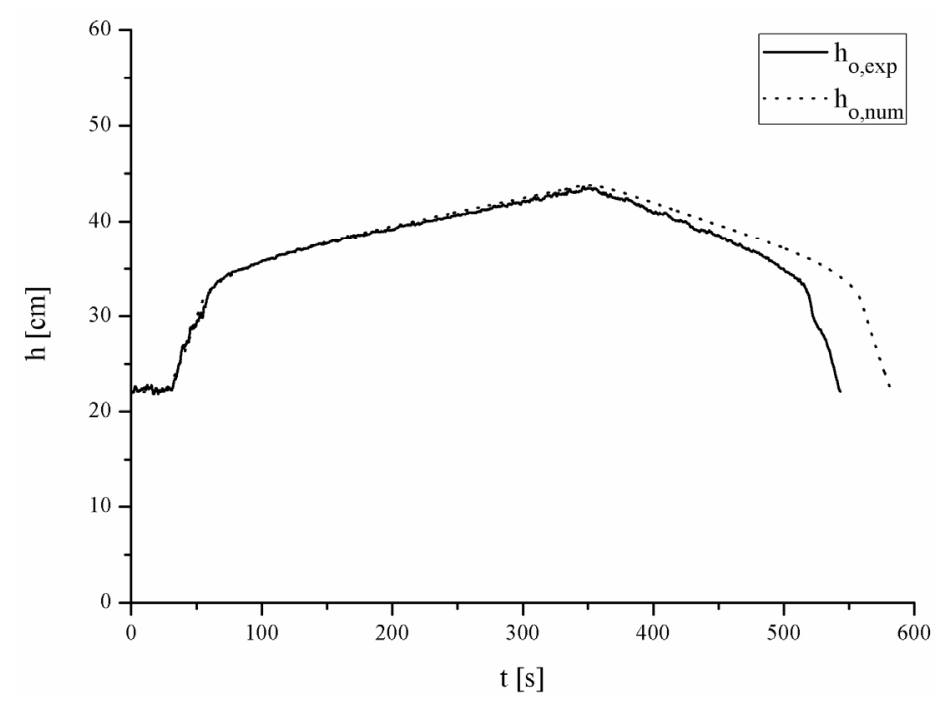

Figure 5. Water level upstream of the floodgate for configuration 2 experiment 


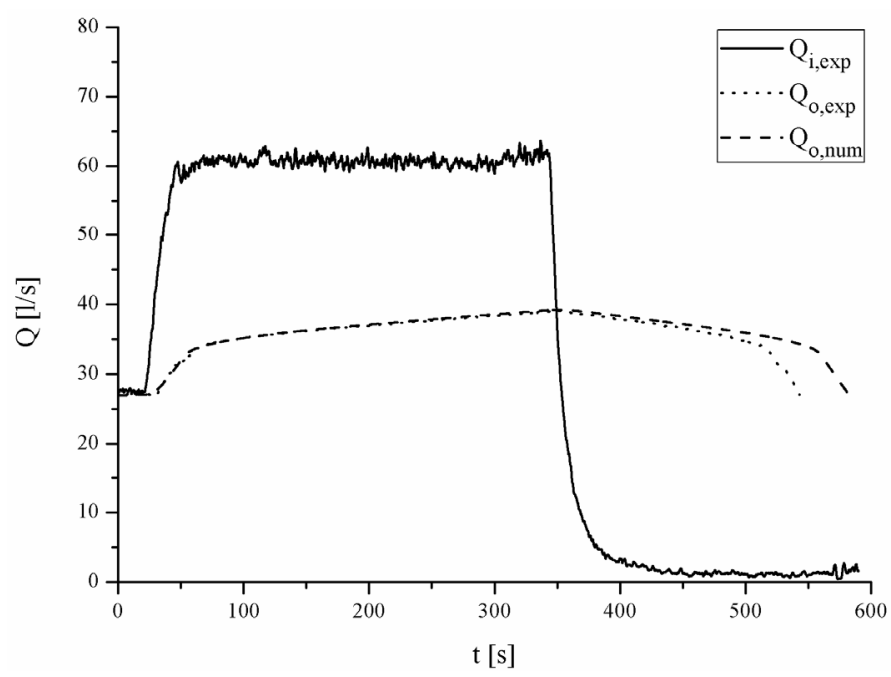

Figure 6. Inflow and outflow hydrographs for configuration 2 experiment

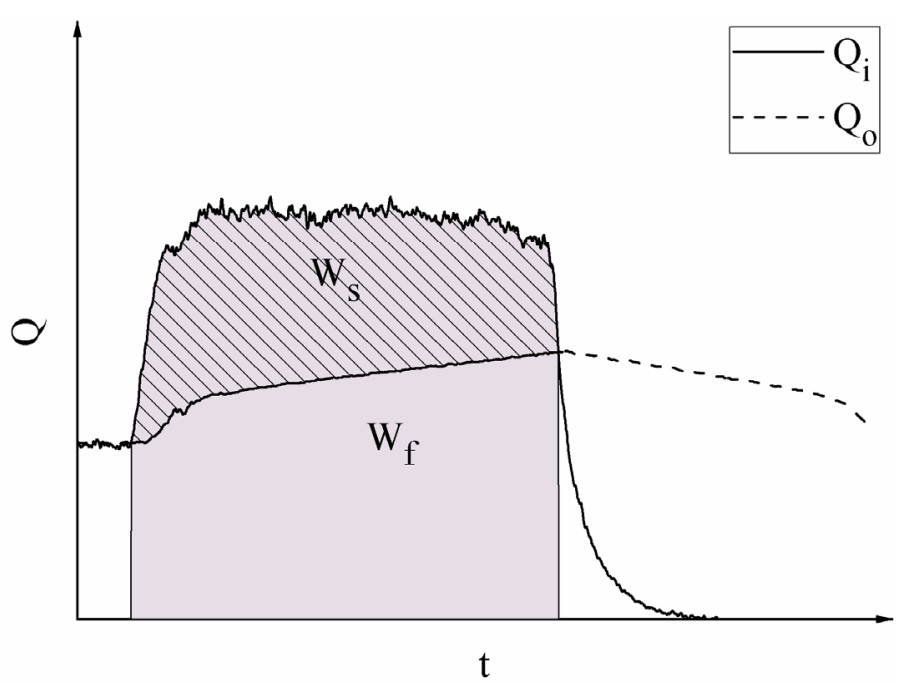

Figure 7. Sketch for flood and storage volume calculation

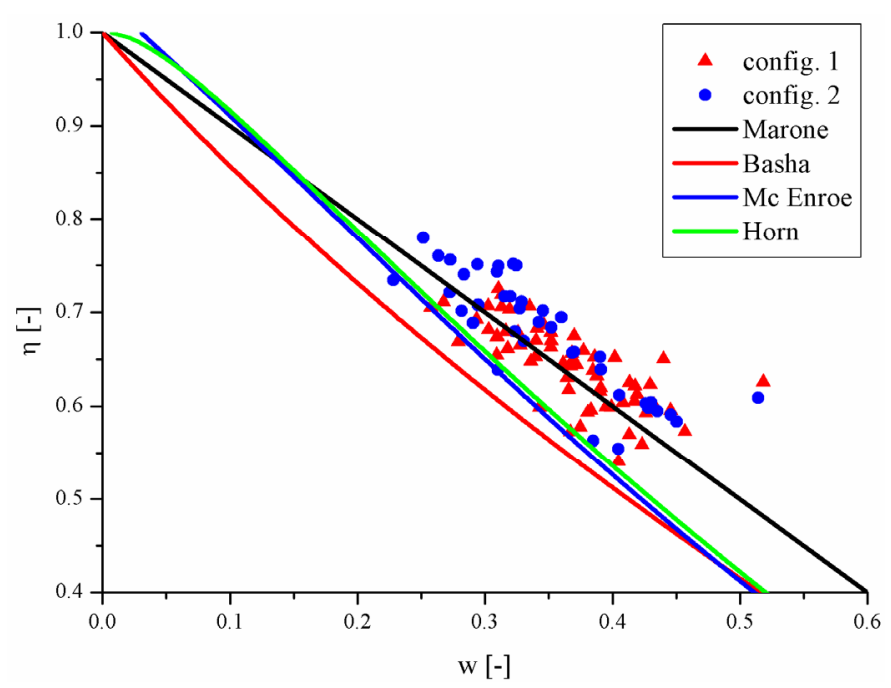

Figure $8 . w-\eta$ experimental data 